\title{
Changes in hydroxyapatite powder properties via heat treatment
}

\author{
Y M Z AHMED ${ }^{1, *}$, S M EL-SHEIKH ${ }^{2}$ and Z I ZAKI ${ }^{1}$ \\ ${ }^{1}$ Ceramic and Refractory Materials Division, Central Metallurgical Research and Development Institute, \\ CMRDI, P.O. Box 87, 11421 Helwan, Egypt \\ ${ }^{2}$ Nano-structured Materials Division, Central Metallurgical Research and Development Institute, CMRDI, \\ P.O. Box 87, 11421 Helwan, Egypt
}

MS received 1 June 2014; accepted 29 July 2015

\begin{abstract}
The properties of hydroxyaptite (HA) powder, especially its physical one, are largely influenced by the heat treatment process. Controlling of these changes is vital in deciding the suitability of applying this powder in wet processing routes for green body fabrication. Chemically, the crystallinity of the HA powder was found to be largely enhanced with the increase in calcination temperatures. In contrary, a high retardation in the carbonate ion content was found. Physically, all the powder properties in terms of particle size, its distribution, pore volume, pore size and surface area are considerably varied with calcination temperatures. It was found that HA powder calcined at both 1000 and $1100^{\circ} \mathrm{C}$ possesses reasonable physico-chemical properties for being applied in wet processing routes. Using heat-treated powder at 1000 and $1100^{\circ} \mathrm{C}$ with $0.3 \mathrm{wt} \%$ sodium polyacrylate (as a dispersing agent) turned out to be beneficial in developing a low viscosity and high turbidity suspensions.
\end{abstract}

Keywords. Hydroxyapatite; heat treatment; particle size; zeta potential; viscosity and turbidity.

\section{Introduction}

Hydroxyapatite (HA) and related calcium phosphate (CP) materials have been widely used as implant materials for many years owing to their close similarity in composition and high biocompatibility with natural bone. ${ }^{1-4}$ Nevertheless, the low mechanical reliability of the sintered HA body limits its use. ${ }^{5,6}$ Lately, a significant effort in defeating this problem has taken place in finding a suitable fabrication route for HA ceramics other than the traditional one (like the dry powder consolidation method). ${ }^{7}$ The colloidal processing route could be promising in this regards. The colloidal approach has the potential for eliminating detrimental heterogeneity, avoiding their reintroduction during the sequential processing steps, and obtaining pieces with intricate shapes similar to human bones. ${ }^{8}$ The most significant and critical step in the successful usage of this route for ceramic fabrication, is the making of highly homogeneous and well-dispersed ceramic suspension prior to molding.

This theme could be accomplished via both (1) controlling the physical properties of the HA powder in terms of particle size, particle size distribution, particle surface charge and surface area and (2) selecting an appropriate dispersing agent in terms of type and amount. It is well recognized that, in order to produce well-stabilized colloidal ceramic suspensions, it is necessary to use powders with low surface area, because powders with high surface area tend to form undesirable agglomerates. ${ }^{9}$ These agglomerates are thought

\footnotetext{
*Author for correspondence (ahmedymz@ hotmail.com)
}

to be 'soft agglomerate' formed by Vander Waals force and it can be easily disintegrated by mixing. ${ }^{10}$ Such agglomerates are known to be difficult to be dispersed owing to their surface charge state ${ }^{11}$ and the producing of very small particles upon mixing. On the other hand, powders with the extremely low surface area have higher density and grain size could be settled out resulting in density heterogeneity in the green body. Therefore, a compromise between these aspects must be reached. In addition, to improve the various properties of the final HA sintered sample, well-stabilized suspensions with a high HA concentration should be prepared. The nature of the surface of HA particles plays a key role in the rheological properties of the formed suspensions. ${ }^{12}$

One way in monitoring the physicochemical properties of HA powder is through calcination process. It was earlier mentioned that the calcination of the HA powder affects its physical properties to a large degree. ${ }^{13-18}$ Their studies were concentrated on the influence of different calcination temperatures on some physical properties of the HA powder in the temperature range from 400 to maximum $1000^{\circ} \mathrm{C}$. They did not expound in their investigation the relation between these changes (physical and chemical properties of HA) with the formation of stabilized suspensions.

Herein different calcination temperatures starting from 800 to $1100^{\circ} \mathrm{C}$ were applied. The effect of these calcination temperatures on the physical and chemical properties of the HA powder was thoroughly investigated. The correlation between the changes in the physical and chemical properties of HA powder for preparing a well-stabilized HA suspension was carried out. Also, the influence of adding different types and amounts of dispersing agents on the viscosity as well 
as turbidity of HA suspension produced from HA powder calcined at various temperatures was studied.

\section{Experimental}

\subsection{Materials}

HA powder used in this project was delivered from Riedelde Haen Co. (Seelze, Germany). The bulk characteristics, which are taken from the manufacturer, indicated that the powder only contains minor amounts of compounds other than calcium and phosphates (see table 1). Two types of dispersant were applied in this investigation. The first is Acumar 9400 which is a water-soluble sodium salt polymer used to disperse and stabilize high-solids mineral slurries. It is an anionic dispersant of sodium polyacrylate polymer (SPA) of solid content 41-43 wt\% with a molecular weight of 30004000. Other dispersant is polyacrylic acid (PAA) dispersant. PAA is a polymer dispersant and it can be used in situations of alkaline and high concentration without scale sediment. The solid content of this type of dispersant is $40 \mathrm{wt} \%$.

\subsection{Characterizations}

X-ray diffraction (XRD, Bruker axs D8, Karlsruhe, Germany) with $\mathrm{Cu}-\mathrm{K}_{\alpha}(\lambda=1.5406 \AA)$ radiation and secondary monochromator was used to identify the type of phases, determine the crystallite size, and the degree of crystallinity of the as-received HA powder. The range of scans was $4^{\circ} \leq$ $2 \theta \leq 70^{\circ}$ for crystalline phase identification and $25^{\circ} \leq 2 \theta \leq$ $26.3^{\circ}$ for crystallite size measurement. Scan step was $0.02 \theta$ with a step time of $2 \mathrm{~s}$. The size of the crystallites responsible for the Bragg reflection of the (002) plane was determined using the well-known Scherrer relationship

$$
D=\frac{k \lambda}{B \cos \theta},
$$

where $D$ is the crystallite diameter in $\AA, k$ the shape constant $(\sim 0.9), \lambda$ the wavelength in $\AA$ ( $\sim 1.5406), \theta$ the Bragg angle in degrees, and $B$ the observed peak width at half-maximum peak height in rad.

On the other hand the crystallinity degree, corresponding to the fraction of crystalline phase present in the examined volume, was evaluated by the relation

$$
B_{002} \sqrt[3]{X_{\mathrm{C}}}=K,
$$

where $X_{\mathrm{C}}$ is the degree of crystallinity, $K$ a constant equal to 0.24 for a very large number of different HA powders, and $B_{002}$ the FWHM (deg) of reflection (002).

The functional group analysis was performed by Fourier transform infrared (FT-IR) spectroscopy. The measurements were carried out in the transmission mode in the mid-infrared range $\left(400-4000 \mathrm{~cm}^{-1}\right)$ at the resolution of $4 \mathrm{~cm}^{-1}$. The studies were performed using the instrument of JASCO 3600 , Tokyo, Japan. For FT-IR measurements, KBr pellets containing the exact weighted amount of the substance examined were prepared.

Morphology of samples was examined using scanning electron microscope (SEM) (JEOL-JSM-5410 Tokyo, Japan) equipped with EDX unit (England, Oxford, ANCK).

The particle size distribution and the mean particle size $\left(d_{50}\right)$ were determined by the laser diffraction method (FRITSCH Model ANALYSETTE 22, Idar-Oberstein, Germany). One gram of the sample was suspended with $10 \mathrm{ml}$ bi-distilled water, then the produced suspension (produced

\begin{tabular}{|c|c|c|c|c|c|}
\hline \multirow{2}{*}{$\begin{array}{l}\text { As-received } \\
\text { HA }\end{array}$} & \multicolumn{4}{|c|}{ Calcined HA } & \multirow{2}{*}{$\begin{array}{l}\text { Corresponding } \\
\text { assignment }\end{array}$} \\
\hline & $800^{\circ} \mathrm{C}$ & $900^{\circ} \mathrm{C}$ & $1000^{\circ} \mathrm{C}$ & $1100^{\circ} \mathrm{C}$ & \\
\hline 3563.8 & 3571.5 & 3571.5 & 3571.5 & 3571.5 & $\mathrm{OH}^{-}$Stretching \\
\hline 3440.4 & 3444.2 & 3444.2 & 3444.2 & 3444.24 & Absorbed $\mathrm{H}_{2} \mathrm{O}$ \\
\hline - & - & 2144.5 & 2144.5 & 2140.6 & Combination of \\
\hline 2078.9 & 2075 & 2075 & 2075 & 2075 & $v_{1}$ and $v_{3}$ modes \\
\hline 2001.7 & 1998 & 1998 & 1998 & 1998 & of $\mathrm{PO}_{4}^{3-}$ \\
\hline 1635.3 & 1635.3 & 1635.3 & 1635.3 & 1635.3 & Water or $\mathrm{CO}_{3}^{2-}$ \\
\hline 1450.2 & 1458 & 1458 & 1458 & - & $\mathrm{CO}_{3}^{2-}$ \\
\hline 1419.4 & 1416 & 1411.6 & 1400 & - & \\
\hline 1095.4 & 1091.5 & 1091.5 & 1091 & 1091 & $v_{3}$ mode of $\mathrm{PO}_{4}^{3-}$ \\
\hline 1045.2 & 1049.1 & 1052.9 & 1049 & 1045 & \\
\hline 964.2 & 964.2 & 964.2 & 964.2 & 964.2 & $v_{1}$ mode of $\mathrm{PO}_{4}^{3-}$ \\
\hline 875.5 & 879.4 & 879 & 879 & - & $\mathrm{CO}_{3}^{2-}$ \\
\hline- & 632.5 & 632 & 632.5 & 632.5 & $\mathrm{OH}^{-}$Stretching \\
\hline 605.5 & 601.7 & 601.7 & 601.7 & 601.7 & $v_{4}$ mode of $\mathrm{PO}_{4}^{3-}$ \\
\hline 570.83 & 570.83 & 570.83 & 570.8 & 570.8 & \\
\hline 470.55 & 474.4 & 470.5 & 470.5 & 470.5 & $v_{2}$ mode of $\mathrm{PO}_{4}^{3-}$ \\
\hline
\end{tabular}

Table 1. FT-IR band position and their corresponding assignments. 
with handshaking) was employed for measuring size analysis. The specific surface area $\left(S_{\mathrm{BET}}\right)$ of the powder was determined by the BET method using a surface area analyser (Autosorb-1, Quantachrome Instruments, USA).

A laser Zetameter (Malvern Instruments Model Zetasizer 2000) was used for zeta potential measurements. A $0.1 \mathrm{~g}$ of sample was placed in $50 \mathrm{ml}$ bi-distilled water with $\mathrm{pH}$ modifiers; having the ionic strength of $2 \times 10^{-2} \mathrm{M} \mathrm{NaCl}$. The suspension was conditioned for $30 \mathrm{~h}$ during which the $\mathrm{pH}$ was adjusted. After shaking, the equilibrium $\mathrm{pH}$ was recorded. Then $10 \mathrm{ml}$ of the suspension was transferred into a standard cell for zeta potential measurement. Suspension temperature was maintained at $25^{\circ} \mathrm{C}$. Zeta potential was measured as a function of $\mathrm{pH}\left(\mathrm{HNO}_{3} 1 \mathrm{M}\right.$ and $\mathrm{NaOH} 1 \mathrm{M}$ were used to adjust the $\mathrm{pH}$ ). Five measurements were taken and the average was reported as the measured zeta potential. The isoelectric point (IEP) was identified at the $\mathrm{pH}$ axis crossing point.

For viscosity measurements, $20 \mathrm{~g}$ of the solid sample was placed with the required concentration percentage of the surfactant (polymer) solutions $\left(100 \mathrm{~cm}^{3}\right)$ in a $200 \mathrm{~cm}^{3}$ volumetric flasks and shaken by a shaker (JANKE \& KUNKEL Type Vx10, Germany). The $\mathrm{pH}$ was adjusted to the desired values using $\mathrm{HCl}$ and $\mathrm{NaOH}$. Then the sample was transferred to the Viscometer Model Anton paar DV-3p, Austria. Three measurements were taken at each point and the average of its was represented as the measured viscosity for the sample.

In turbidity experiments, $0.1 \mathrm{~g}$ dry sample was placed with the required concentration of surfactant (polymer) solutions $\left(50 \mathrm{~cm}^{3}\right)$ in a $100 \mathrm{~cm}^{3}$ volumetric flasks and shaken by a shaker (JANKE \& KUNKEL Type Vx10, Germany). The pH was adjusted to the desired values using $\mathrm{HCl}$ and $\mathrm{NaOH}$. The solution was shaken for $30 \mathrm{~h}$ at controlled room temperature of $25^{\circ} \mathrm{C}$. Then, the samples were transferred to the turbidity Inst. Model HANNA Instruments, Sweden, range 0.000-1.000 BTU. The measurements were replicated for three times for each sample and the average was taken as a measured for the turbidity degree.

\section{Results and discussion}

\subsection{Effect of calcination temperatures on the properties of calcined powder}

3.1a XRD analysis: Figure 1 shows the XRD patterns of the as-received HA powder and the samples after calcining at various temperatures. The XRD peaks of all five diffraction patterns are compared with that of standard HA in the powder diffraction file (PDF card \# 9-432). A good agreement between the experimental data (for all samples) and the standard hexagonal HA structure (PDF card \# 9-432) both in terms of intensity and $d$-spacing was obtained. Particularly the strong diffraction peaks corresponding to HA at $2 \theta$ position of 31.78 (211 plane) together with other two peaks at 32.266 (112 plane) and 32.951 (300 plane) confirmed that both as-received powder and that calcined at various temperatures are pure HA of hexagonal structure. ${ }^{19}$ However, no peaks were detected at $2 \theta$ of $29.4^{\circ}$ and $39.93^{\circ}$ which are characteristic peaks of calcium carbonate (calcite) ${ }^{20}$ for both asreceived powder and that calcined at various temperatures. This confirmed that the different calcination temperatures not influenced the composition of the HA structure of the asreceived sample. On the other hand, no extraneous phases were detected in the examined $2 \theta$ range either before or after heat treatment.

In addition, the $\mathrm{XRD}$ patterns revealed the following interesting points:

(1) Although the as-received powder is composed of a pure HA it is clear from the pattern that it is present in poorly crystalline phase together with amorphous phase. Also the overlapping of the (211) and (112) peaks at $2 \theta \sim 32$ is clearly noticeable. This overlapping is an indication for the presence of HA phase in carbonated form. ${ }^{21}$

(2) As the calcination temperature is increased from 800 to $1100^{\circ} \mathrm{C}$, several HA lines become more distinct (especially at higher calcination temperature) which is an indication of the increasing the crystallinity degree. Also the width of the lines becomes narrower, which suggest an increasing in the crystalline size with the increase in the calcination temperature.

Accordingly, both crystallinity degree and crystalline size variation with calcination temperature were evaluated using the XRD pattern with the aid of simple equations.

For the degree of crystallinity measurements, the equation of Landi et $a l^{22}$ was applied (equation (2)). Whereas, the full-width under half-maximum for the (002) planes for samples treated at various calcination temperatures is given in figure 2.

Based on equation (2), the variation in the degree of crystallinity of HA sample with different calcination temperatures was calculated and given in figure 3. It was pointed out that the crystallinity degree of the as-received powder was $8 \%$ is largely increased to $78 \%$ with the increase in calcination temperature to $1000^{\circ} \mathrm{C}$. While beyond $1000^{\circ} \mathrm{C}$ a slight increase in the crystallinity degree was observed at $1100^{\circ} \mathrm{C}$. The similar phenomenon was recorded by various authors. $^{23-26}$

On the other hand, the line broadening of (002), (211), (300), (202), (310), (222) and (213) reflections was used to measure the mean crystalline size of HA samples using the Scherrer relationship (equation (2)).

The variation in crystalline size of HA samples with different calcination temperatures was calculated and presented in figure 4. It was noticed that the crystalline size of HA samples was increased from $28 \mathrm{~nm}$ for as-received powder to $190 \mathrm{~nm}$ for powder calcined at $1100^{\circ} \mathrm{C}$. The increase in crystalline size is found to follow two distinct steps. One of the as-received powder to powder calcined at $800^{\circ} \mathrm{C}$, where the increase in crystalline size is slow from 28 to $65 \mathrm{~nm}$, respectively. The other, in the high calcination temperatures ranges from 800 to $1100^{\circ} \mathrm{C}$ where the size is increased rapidly from 65 to $190 \mathrm{~nm}$, respectively. The slow growth rate in the first 


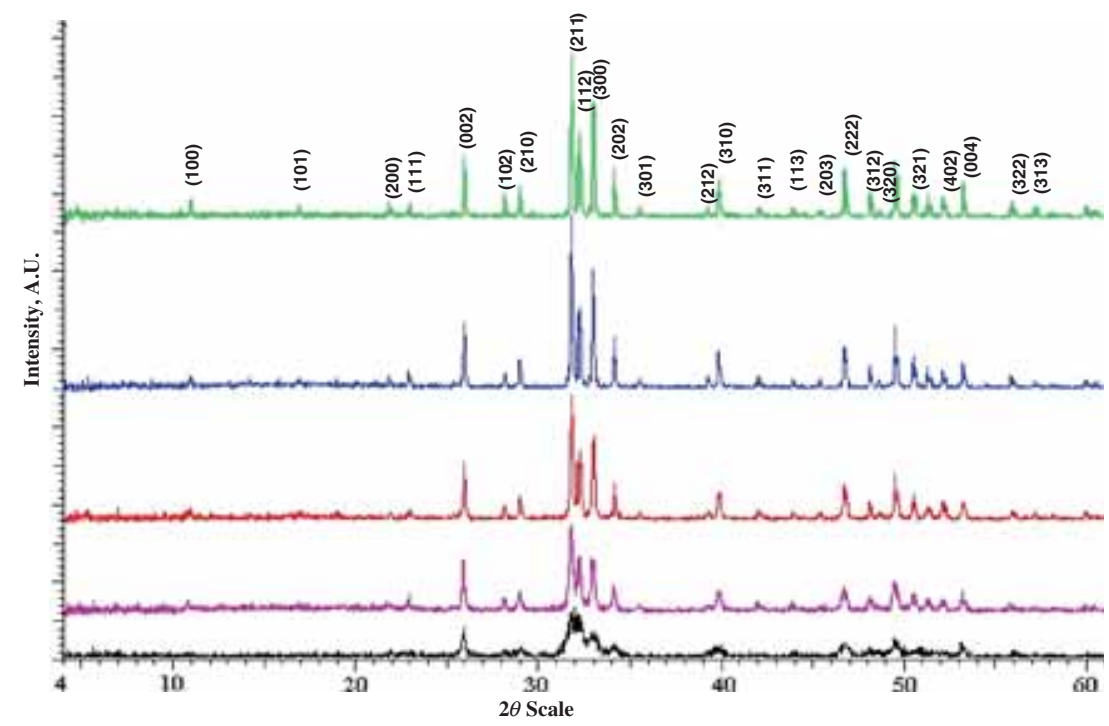

Figure 1. XRD patterns of hydroxyapatite powder treated at different calcination temperatures.

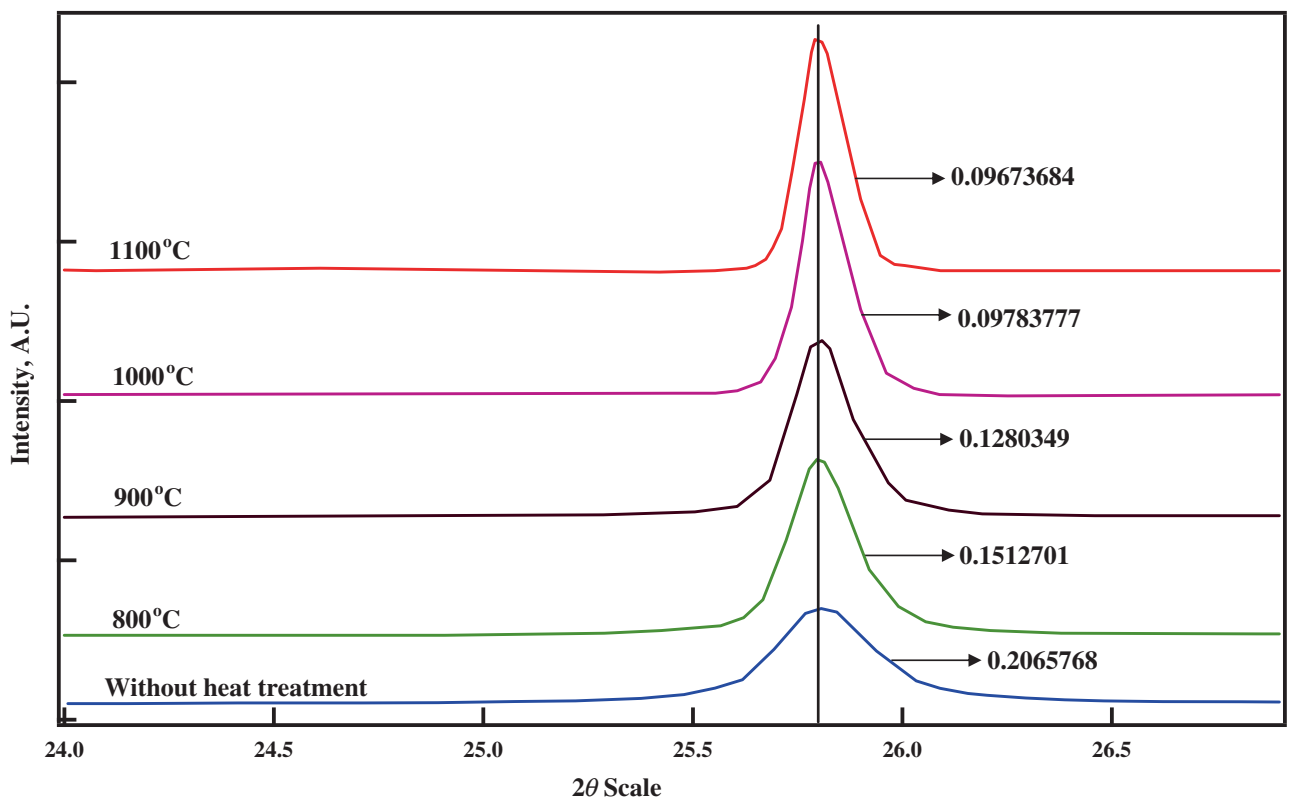

Figure 2. FWHM for the (002) plane of hydroxyapatite at different calcination temperatures.

part may be ascribed to the crystallization of a large number of particles (confirmed from the low crystallinity degree of the as-received powder with the occurrence of amorphous phase structure). In this stage crystallization is the predominant mechanism. In the second part growth of the crystallized particles takes place at a rapid rate with a diffusion-controlled mechanism beside crystallization of other particles. The diffusion-controlled coarsening of the powder on heating leads to grain growth of the crystallized particles results in increasing the crystalline size. ${ }^{27}$ However, beyond $800^{\circ} \mathrm{C}$ the two mechanisms (crystallization and diffusion) are simultaneously occurring at a high rate. Figures 3 and 4 indicate that beyond $800^{\circ} \mathrm{C}$ a rapid increase in both crystallinity degree and crystalline size is occurring. This observation is rather confirmed from the SEM analysis of as-received powder and powder calcined at various temperatures as shown in figure 5 . These figures revealed that a considerable enhancement in grain growth was clearly marked with the increase in calcination temperatures.

3.1b FT-IR analysis: To study the evolution of functional groups in the as-received HA powder sample and that calcined at different temperatures, the FT-IR of these samples were analysed. Functional groups that normally observed in the FT-IR of calcium phosphate-based materials are $\mathrm{PO}_{4}^{3-}$, $\mathrm{OH}^{-}, \mathrm{HPO}_{4}{ }^{2-}$ and $\mathrm{CO}_{3}$ in the range of $4000-300 \mathrm{~cm}^{-1} .^{28}$ 


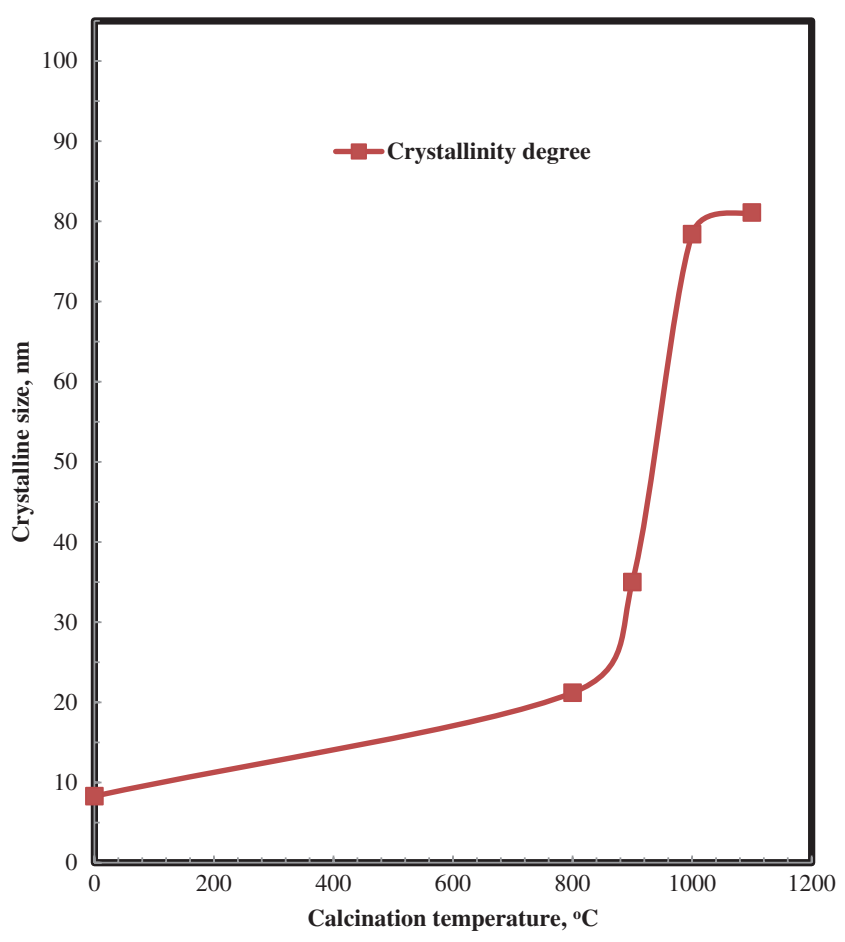

Figure 3. Effect of calcination temperatures on the crystallinity degree of HA samples.

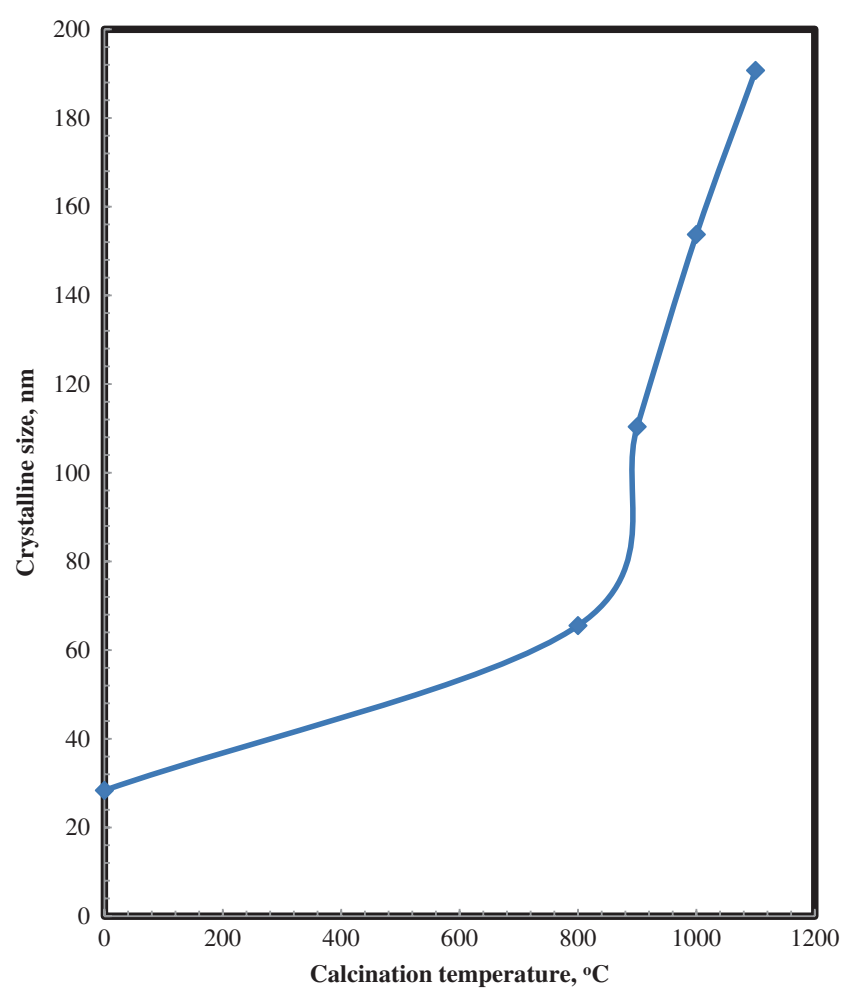

Figure 4. Effect of different calcination temperatures on the crystalline size of HA samples.

There are four modes of $\mathrm{PO}_{4}^{3-} ; v_{1}, v_{2}, v_{3}$ and $v_{4}$ which gives bands at around 958, 500-400, 1100-1019 and 605$530 \mathrm{~cm}^{-1}$, respectively. ${ }^{28}$ On the other hand, there are three modes of $\mathrm{OH}^{-}$ions; stretching, vibration and translation, which give bands at $3700-250,630$ and $390 \mathrm{~cm}^{-1}$, respectively. ${ }^{29}$ The $\mathrm{HPO}_{4}{ }^{2-}$ ions are observed at $875 \mathrm{~cm}^{-1}$ band. However, overtone and combination of $\nu_{3}$ and $v_{1}$ modes of $\mathrm{PO}_{4}^{3-}$ or even $\mathrm{HPO}_{4}^{2-}$ appear in the $2200-1950 \mathrm{~cm}^{-1}$ region. ${ }^{29,30}$ Water molecules appear at $1642 \mathrm{~cm}^{-1}$ but may be obscured by the $\mathrm{CO}_{3}{ }^{2-}$ band. ${ }^{30,31}$ The $\mathrm{CO}_{3}{ }^{2-}$ ions, which replace $\mathrm{PO}_{4}^{3-}$ ions in the $\mathrm{HA}$ lattice (designated as 'B-type' carbonate) appear at about 1410 and $1450 \mathrm{~cm}^{-1}$. While the $\mathrm{CO}_{3}^{2-}$ that are supposed to replace $\mathrm{OH}^{-}$ions in the HA lattice (designated as 'A-type' carbonate) gives bands at 1455 and $1540 \mathrm{~cm}^{-1} .32$

Figure 6 shows the FT-IR spectra of both as-received HA powder and sample calcined at various temperatures. The band position and their respective assignments are given in table 1. Both figure 6 and table 1 revealed that there are some common features of the spectra produced from various samples. Whereas, there are many differences between these spectra are clearly noticeable.

The common features between the five spectra of different samples (as-received and calcined at different temperatures) are:

(1) Appearance of absorption bands in the range of $\sim 964$, 1045,570 and $635 \mathrm{~cm}^{-1}$ are characteristic bands of crystallized apatite phase. ${ }^{33}$

(2) All vibration modes of $\mathrm{PO}_{4}^{3-}\left(v_{1}, v_{2}, v_{3}\right.$ and $\left.v_{4}\right)$ are clearly identified in all spectra. Bands appeared at $\sim 964,470,1045-1095$ and $570-605 \mathrm{~cm}^{-1}$ are characteristic bands for $v_{1}, v_{2}, v_{3}$ and $v_{4}$ stretching modes of $\mathrm{PO}_{4}{ }^{3-}$ ions, respectively.

(3) Bands at 3444 and $1635 \mathrm{~cm}^{-1}$ are relevant to the bending modes of hydroxyl groups in the absorbed water. While bands at $3571 \mathrm{~cm}^{-1}$ as well as $633 \mathrm{~cm}^{-1}$ (not observed only in the as-received powder) are assigned to the stretching vibration of hydroxyl groups in the crystal structure of HA. ${ }^{34-37}$

However, there are many differences between the spectrum of the as-received HA sample and that calcined at various temperatures. These differences are pronounced in the appearance of new peaks with the decrease in intensities or even disappearance of the others. The followings are the main differences between the spectra that are noticeable from figure 6:

(1) In the spectrum of as-received $\mathrm{HA}$, bands of $\mathrm{CO}_{3}^{2-}$ was clearly detected in the region around 1460, 1416 and $875 \mathrm{~cm}^{-1}$. The band at $\sim 875 \mathrm{~cm}^{-1}$ indicates the $v_{2}$ mode of $\mathrm{CO}_{3}^{2-}$ group. ${ }^{38}$ While, Moens et $a l^{39}$ and $\mathrm{Xu}$ et $a l^{33}$ have ascribed the appearance of bands at 872,1417 and $1460 \mathrm{~cm}^{-1}$ to the presence of B-carbonated HA in which some of the $\mathrm{CO}_{3}^{2-}$ ions substitute the $\mathrm{PO}_{4}^{3-}$ ions in the HA structure. The XRD diffraction pattern of this sample (figure 1), not reveals any peaks characteristics for the presence of such compound (carbonated HA). This could attribute to the fact that, the strongest reflections of this compound arising from the (112) plane is 


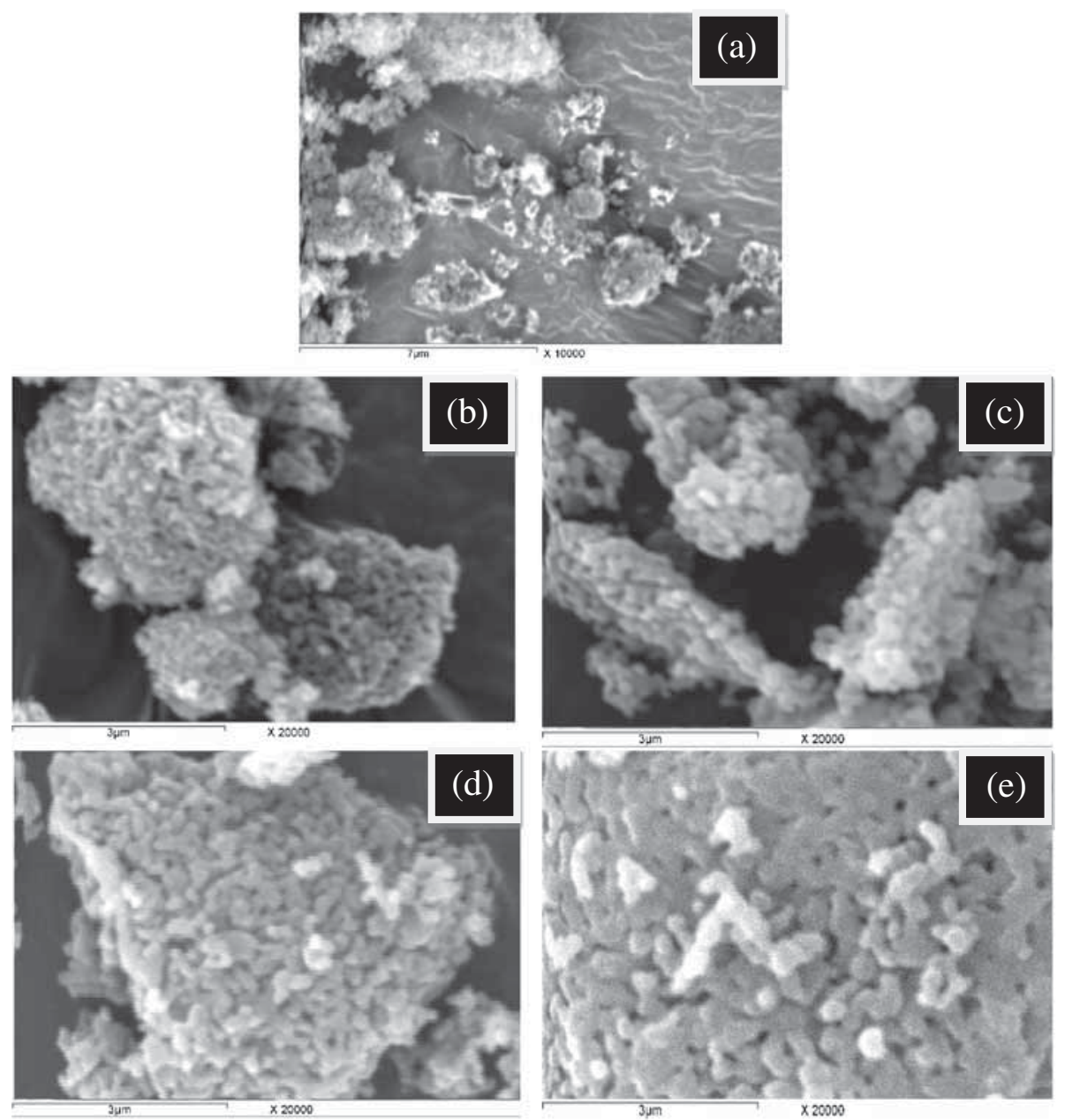

Figure 5. SEM micrographs for hydroxyapatite powder calcined at various temperatures: (a) as-received, (b) $800^{\circ} \mathrm{C},(\mathbf{c}) 900^{\circ} \mathrm{C}$, (d) $1000^{\circ} \mathrm{C}$ and (e) $1100^{\circ} \mathrm{C}$.

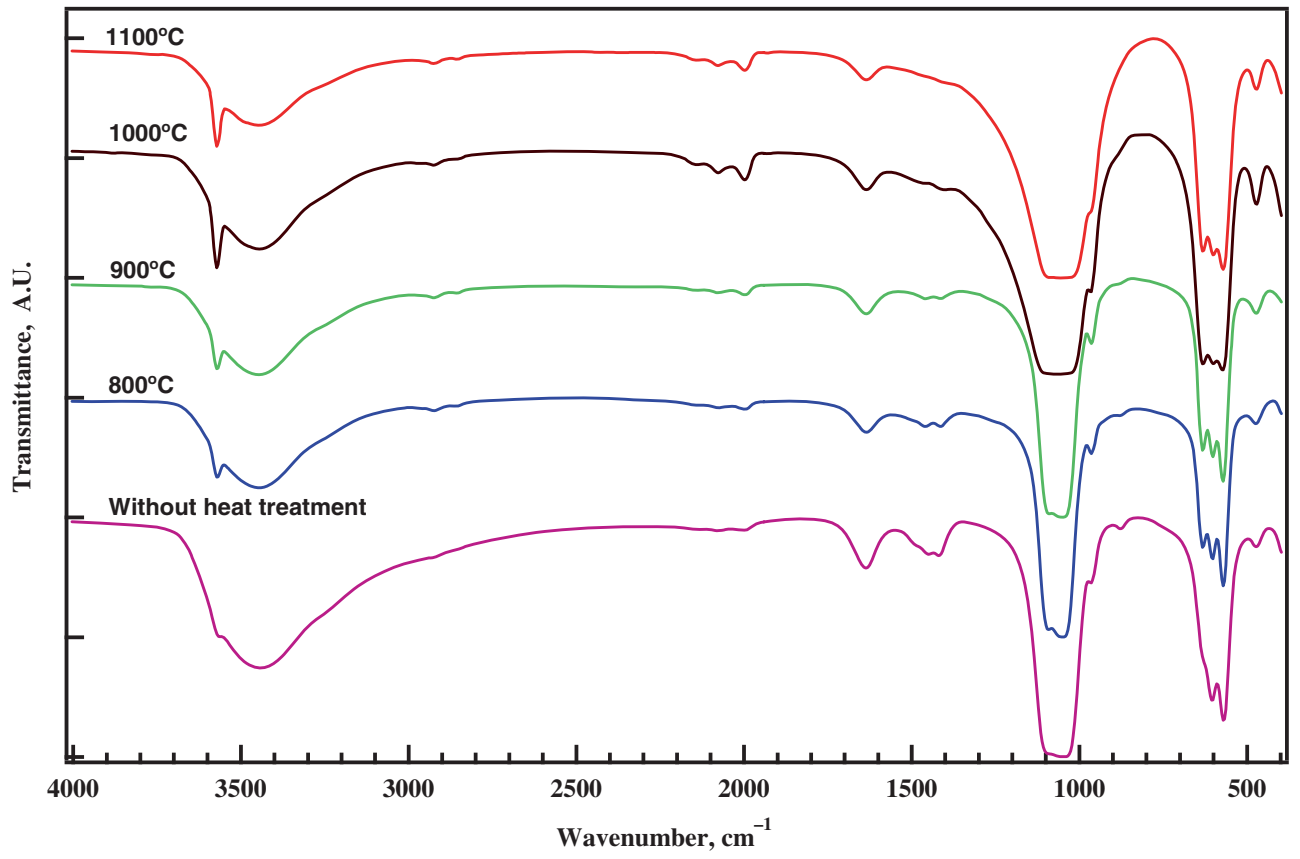

Figure 6. FT-IR spectra for hydroxyapatite treated at different calcination temperatures. 
lying at $2 \theta$ of 32.199 , which almost overlaps with the $60 \%$ relative intensity reflection of $\mathrm{HA}$ arising from the (112) plane that lies at $2 \theta$ of 32.169 . In addition, the lack of other peaks corresponding to the carbonated HA in the XRD of as-received sample may be due to incomplete crystallization of this phase. This interpretation is consistent with a crystallinity degree calculation for such sample which revealed that this sample is nearly amorphous. By increasing the calcination temperatures a sharp decrease in the intensities of these bands (corresponding to $\mathrm{CO}_{3}^{2-}$ ) is detected. This indicates the elimination of $\mathrm{CO}_{3}^{2-}$ due to the release of volatile gas with the increase in temperature. However, the spectra indicate that these bands are almost disappearing for the sample calcined at $1000^{\circ} \mathrm{C}$ while it completely disappears for sample calcined at $1100^{\circ} \mathrm{C}$. This indicates that samples calcined at both 1000 and $1100^{\circ} \mathrm{C}$ are composed of crystallized HA without the presence of any of carbonated HA.

(2) In the calcined samples, a new peak at $632.5 \mathrm{~cm}^{-1}$ (which not observed in the as-received sample) is clearly detected. This band is assigned to the stretching mode of $\mathrm{OH}^{-}$ion, which an indication of the presence of structural $\mathrm{OH}^{-}$. The presence of this band in the spectra of calcined samples confirming the formation of characteristic apatite structure ${ }^{12}$ and is indicative for the good crystallinity of HA sample. ${ }^{19}$ This result is in good agreement with XRD data which revealed that the crystallinity degree is largely increased with the increase in calcination temperatures.

(3) The bands observed at 1635.3 and $3444 \mathrm{~cm}^{-1}$ are assigned for the absorbed $\mathrm{H}_{2} \mathrm{O}$ which is quite usual to present in all HA samples. A high decrease in the intensities of these bands is clearly visible with the increase in calcination temperatures. This is an indication of the loss of $\mathrm{H}_{2} \mathrm{O}$ molecules during calcination. ${ }^{19}$

(4) It could be easily noticed that the intensity of the peak appears at 3571 for as-received sample is largely increased with the increase in calcination temperatures and also become much sharper. This band is assigned to the stretching vibration mode of $\mathrm{OH}$ group, and it is a characteristic feature of apatite structure. Increasing the intensity of this band with the appearance of new bands in the range of 1900-2200 $\mathrm{cm}^{-1}$ (assigned to $v_{1}$ and $v_{3}$ modes of $\mathrm{PO}_{4}^{3-}$ ion $)^{40}$ is an evidence for increasing the crystallinity degree of HA sample with the increase in calcination temperature.

3.1c Particle size and surface area: The effect of different calcination temperatures on the particle size and its distribution of HA powder is shown in figure 7. The mean particle size was found to increase from $\sim 3.4 \mu \mathrm{m}$ for the as-received sample to $\sim 16.9 \mu \mathrm{m}$ for sample calcined at $1100^{\circ} \mathrm{C}$. Figure 8 shows the variation in the mean particle size of HA samples calcined at different temperatures. However, there was no phase transformation detected in the XRD pattern (as shown in figure 1). This means that the increase in the mean

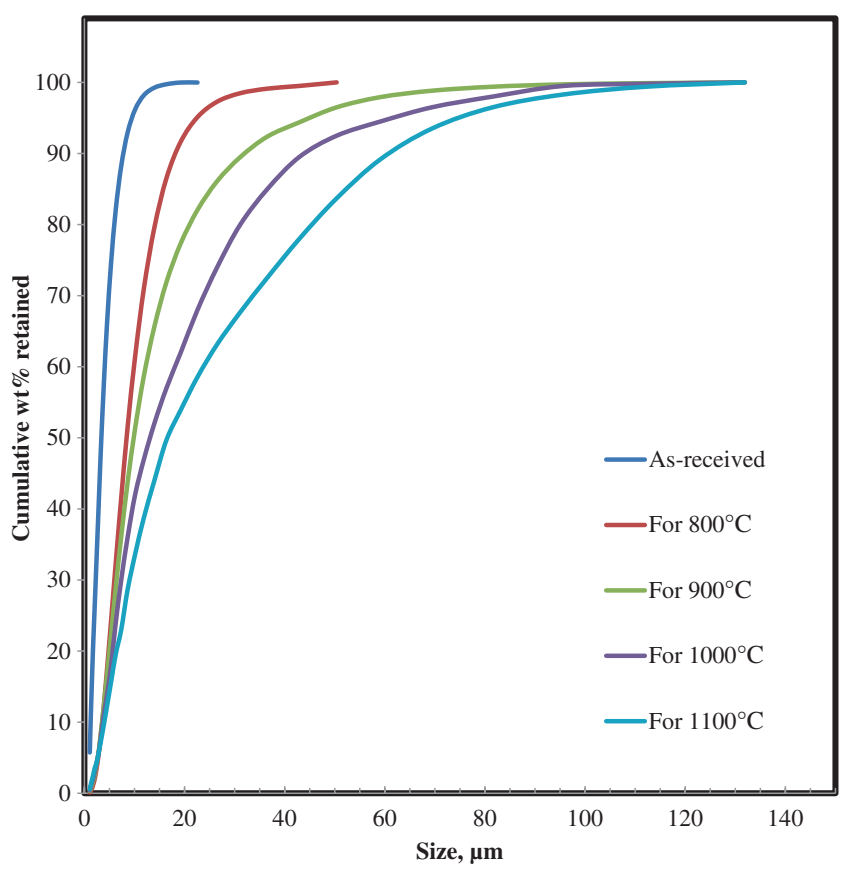

Figure 7. Cumulative weight retained for hydroxyapatite powder treated at different calcination temperatures.

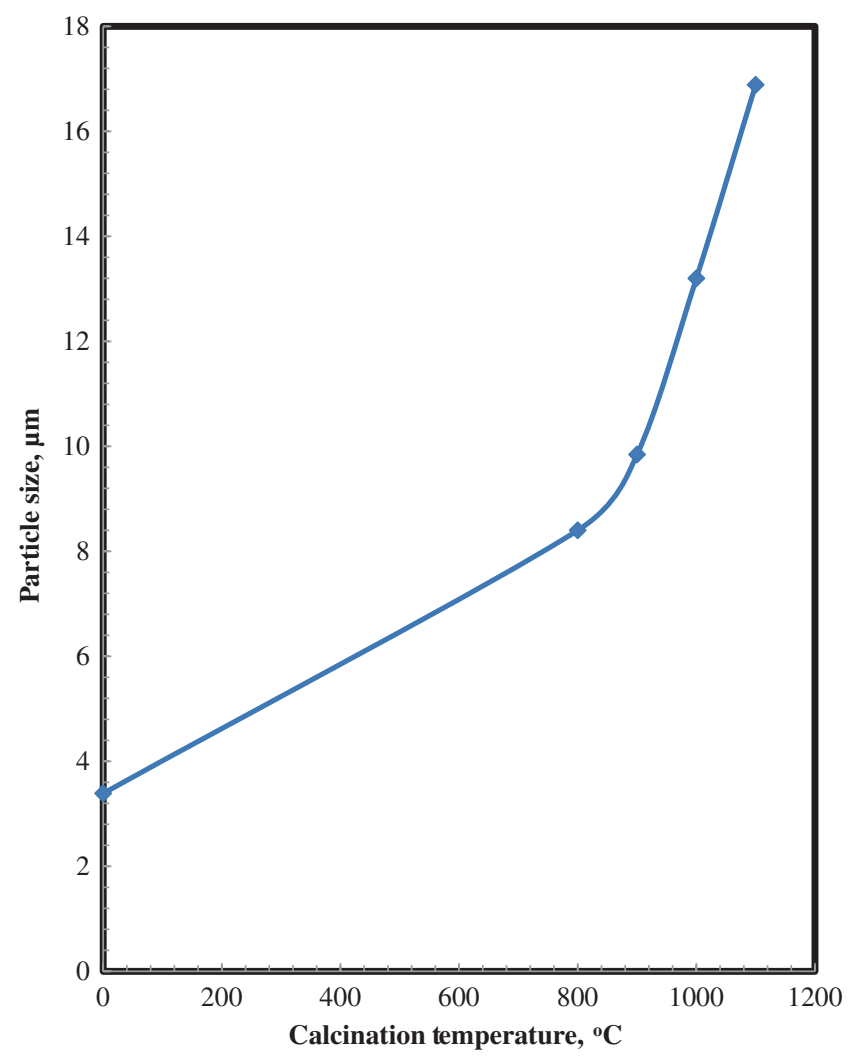

Figure 8. Effect of calcination temperatures on the mean particle size of calcined samples.

particle size is mainly the result of the necking of particles during the calcination process ${ }^{10}$ which favour a grain growth of HA particles as previously described in the reason 
of increasing the crystalline size with calcination temperature. Increasing the calcination temperature gives the system adequate kinetics to permit further growth of HA grains. ${ }^{24}$

The growth of HA grains with temperature can be ascribed by nucleation-aggregation-agglomeration growth mechanism. ${ }^{41}$ According to this mechanism, HA particle growth through three steps: (a) nucleation and growth to form HA nano-crystallites, (b) aggregation of elemental nano-crystals by molecular attraction ${ }^{42}$ of different nano-metric/colloidal scale forces which cause surface free energy minimization and (c) further crystal growth, at a constant residual supersaturation, acting as a cementing agent inside the aggregate to form agglomerates. The increase in particle size with temperature takes place by the aggregation of these agglomerated particles to form large particle. On the other hand, this mechanism of grain growth with temperature could be confirmed from the increasing of crystalline size with temperature as deduced from figure 4.

Figure 9 shows the adsorption isotherm of the as-received and calcined samples, while the specific surface area of different samples is tabulated in table 2. It was found that, the as-received HA sample has the highest value of specific surface area of $\sim 74 \mathrm{~m}^{2} \mathrm{~g}^{-1}$ while it is largely decreased for calcined samples. The specific surface area of calcined

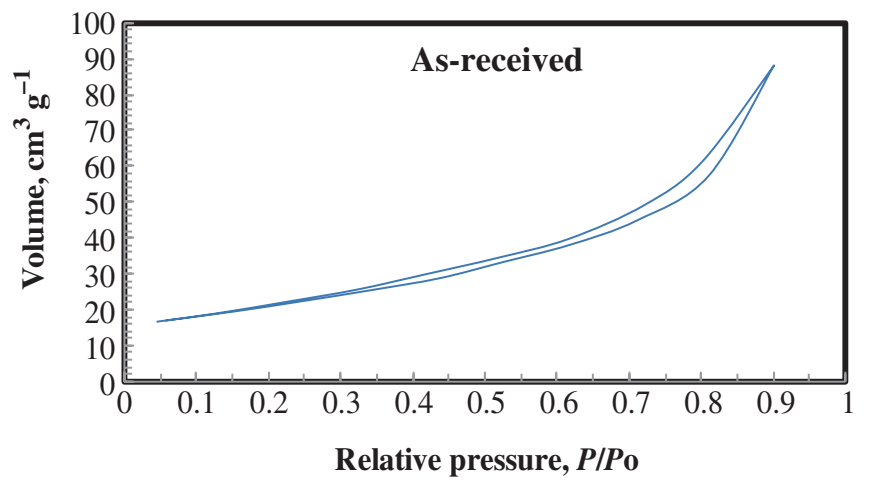

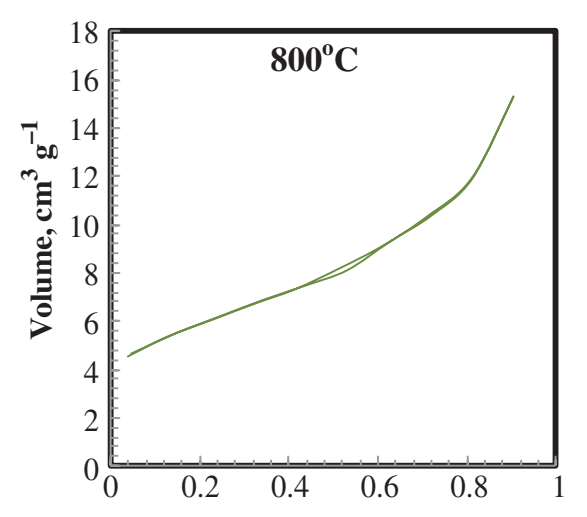

Relative pressure, $P / P$ o

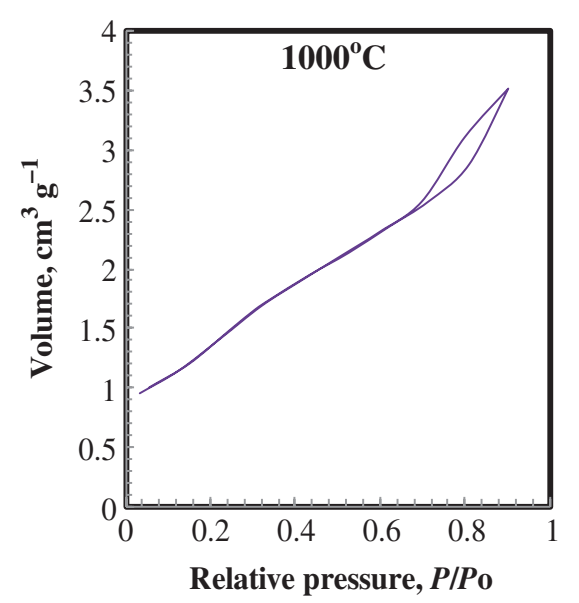

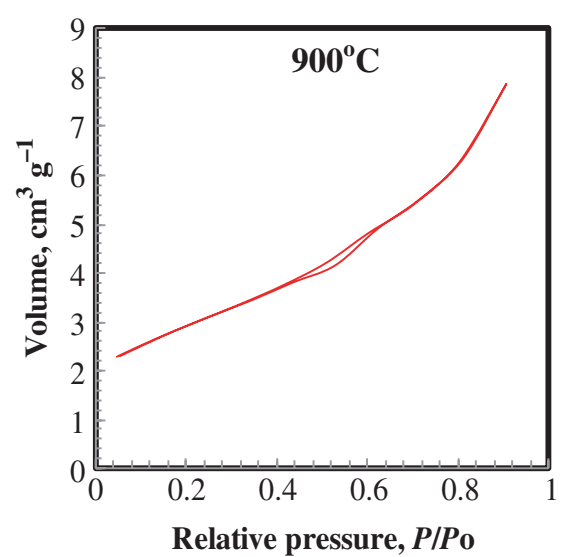

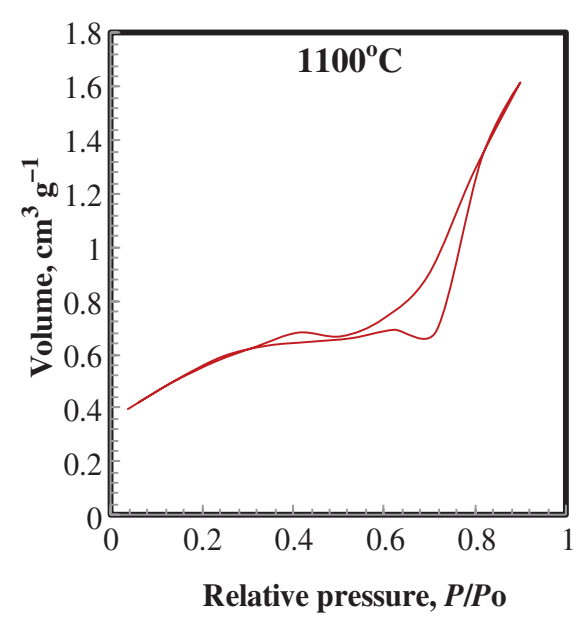

Figure 9. Adsorption-desorption isotherm for hydroxyapatite powder treated at different calcination temperatures. 
Table 2. Effect of calcination temperatures on the surface area of HA samples.

\begin{tabular}{lccccc}
\hline & As-received & \multicolumn{4}{c}{ Calcined HA } \\
\cline { 3 - 6 } Sample type & $\mathrm{HA}$ & $800^{\circ} \mathrm{C}$ & $900^{\circ} \mathrm{C}$ & $1000^{\circ} \mathrm{C}$ & $1100^{\circ} \mathrm{C}$ \\
\hline Surface area, $\mathrm{m}^{2} \mathrm{~g}^{-1}$ & 73.867 & 20.026 & 10.091 & 5.157 & 1.895 \\
\hline
\end{tabular}

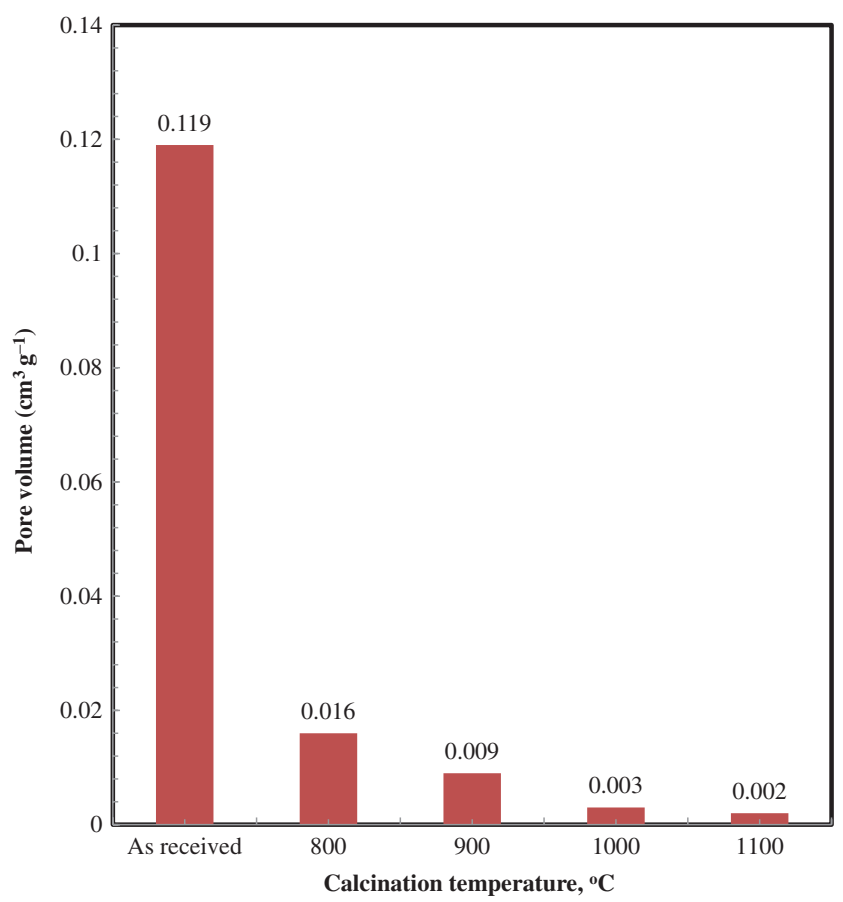

Figure 10. Effect of calcination temperatures on the pore volume of hydroxyapatite powder.

powders was found to be $\sim 20, \sim 10, \sim 5$ and $\sim 2 \mathrm{~m}^{2} \mathrm{~g}^{-1}$ for sample calcined at $800,900,1000$ and $1100^{\circ} \mathrm{C}$, respectively. The decrease in specific surface area with the increase in calcination temperature was attributed to the increase in the particle size of HA powder upon calcination. ${ }^{21,43}$

On the other hand, the pore volume as well as the pore size distribution of HA powder as a function of calcination temperatures are shown in figures 10 and 11, respectively. It was found that the pore volume is largely decreased with the increase in calcination temperatures, while it is approximately eliminated when the powder is calcined at $1100^{\circ} \mathrm{C}$. However, the pore size distribution confirmed that all powder has a wide pore size distribution started from mesoporous range $2-50 \mathrm{~nm}$ to macroporous region $>50 \mathrm{~nm}$. It is also confirmed that the overall porosity degree is largely reduced with the increase in temperature and even eliminated when the calcination temperatures reached $1100^{\circ} \mathrm{C}$. This parameter is very important when dealing with preparation of wellstabilized colloidal suspensions from HA powder. Because beside chemical composition and surface area of the powder, pore volume and its distribution is another factor which is largely influenced the suspensions fluidity. For powder with high pore volume a part of the liquid in a suspension is

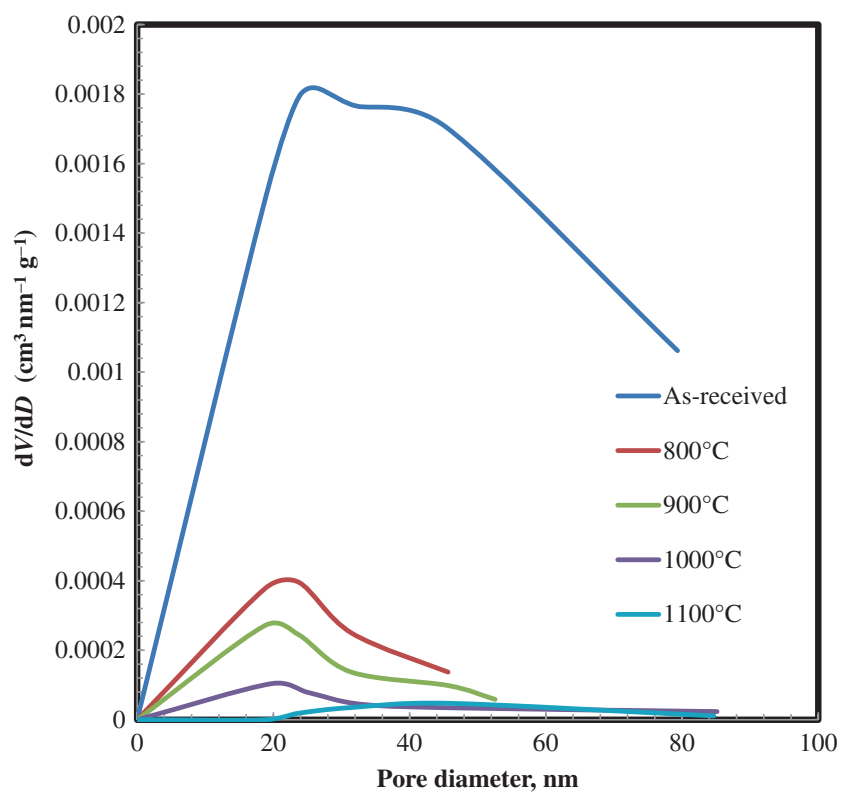

Figure 11. Effect of calcination temperatures on the pore size distribution hydroxyapatite powder.

immobilized inside the pores. Therefore the effective volume of liquid would be higher with utilization of lower porosity powder. ${ }^{9}$ Accordingly decreasing the pore volume and its distribution of the powder will enhance to a large extent the stability of the suspensions produced from it.

\subsection{Effect of calcination temperatures on zeta potential of powder}

It is well known that the surface properties of HA particles are very much sensitive to the history of the powder processing route as well as the heat treatment process. ${ }^{44}$ The heat treatment process was found to be an important step in achieving a sufficient surface charge and a high zeta potential value which is a prerequisite for the preparation of a suspension with a sufficiently high solid loading. . $^{8} 43-45$

Figure 12 shows the zeta potential as a function of $\mathrm{pH}$ for as-received HA sample as well as samples calcined at various temperatures. The deviation of isoelectric point to a more acidic region with the increase in calcination temperatures is clearly noticeable. This behaviour could attribute to the presence of the carbonate group in the as-received HA powder. The presence of this group changes the surface behaviour of the powder making a shift in the isoelectric point (IEP) to a higher basic region. ${ }^{21}$ With increasing calcination 


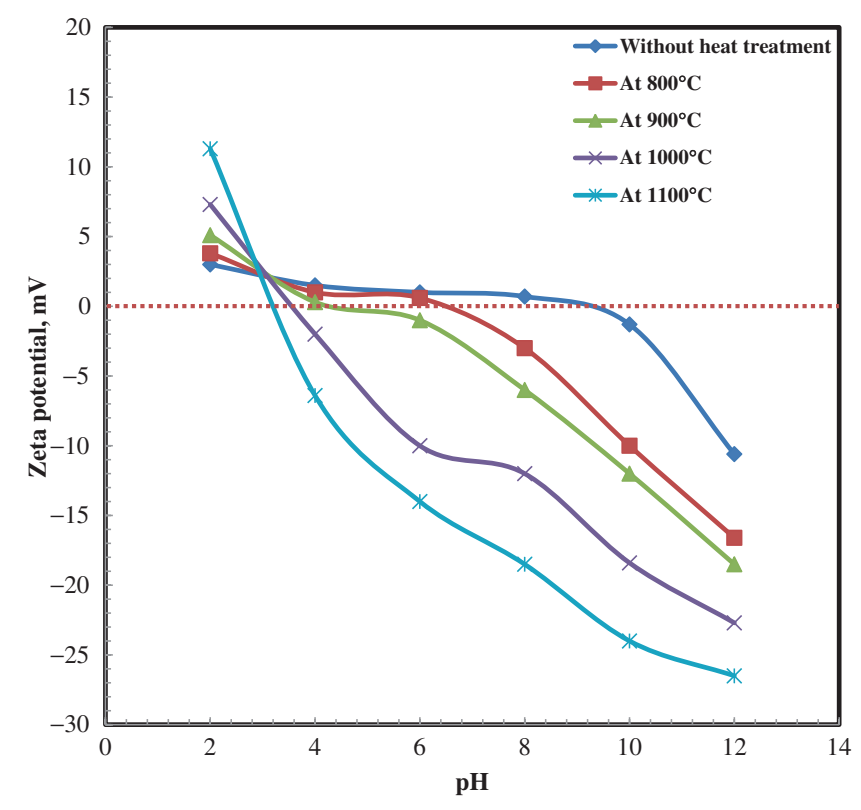

Figure 12. Zeta potential-pH relationship of hydroxyapatite powder treated at different calcination temperatures.

temperatures the quantity of carbonate ions in calcined samples is largely decreased till it completely eliminated at the $1100^{\circ} \mathrm{C}$ (as confirmed from the FT-IR data shown in figure 6), which interpret the shifting in the IEP of these powders to a more acidic region. However, it could be also noticed that by increasing the $\mathrm{pH}$ value, more negative charge established on the surface of HA particles for both as-received and calcined samples. The highest negative charges was attained at $\mathrm{pH}$ of $\sim 11$ at which zeta potentials were found to be $\sim-29, \sim-20, \sim-9, \sim-8$ and $\sim-3$ for sample calcined at 1100, 1000, 900, 800 and as-received, respectively. The highest negative charge was achieved for sample calcined at 1000 and $1100^{\circ} \mathrm{C}$. This fact, with other facts deduced from the previous study of the characteristics of these two samples, including well-crystallized HA (almost pure from carbonate ions and low surface area) make these two samples as the best for performing the rest of the study to evaluate the rest of parameters in order to prepare a well-stabilized HA suspension of high solid loading.

\subsection{Effect of type and amount of dispersing agent on zeta potential}

When HA particles dispersed into aqueous media it might have various ions on their surfaces (such as $\mathrm{Ca}^{2+}, \mathrm{CaOH}^{+}$, $\mathrm{PO}_{4}^{3-}, \mathrm{HPO}_{4}^{2-}, \mathrm{H}_{2} \mathrm{PO}_{4}^{-}$and $\mathrm{CaH}_{2} \mathrm{PO}_{4}^{+}$). Accordingly, $\mathrm{HA}$ suspension can be stabilized by the using of anionic polyelectrolyte. ${ }^{46}$ The study on the effect of calcination temperatures on zeta potential of HA particles revealed that these particles are thermodynamically stable in the alkaline $\mathrm{pH}$ region. It is recognized that the anionic type dispersing agents help to develop high zeta potentials in the neutral or alkaline $\mathrm{pH}$ regions and are more effective in stabilizing HA suspensions than non-ionic dispersant. ${ }^{47}$ These anionic polyelectrolytes modify the surface chemistry of powder in order to produce repulsive inter-particle forces that promote dispersion. Polyacrylate dispersant (represent a large group of anionic polyelectrolyte) proved to be effective dispersing agents for both clay- and non-clay-based ceramics, through an electrosteric mechanism of dispersing action. The combination of electrostatic and steric stabilization mechanisms (electrosteric mechanism) is important, especially in case of high solids concentration where the average inter-particle distance is short. ${ }^{48,49}$ Accordingly, two types of polyacrylate dispersants namely PAA and sodium polyacrylate (SPA) were applied to further investigations for stabilizing HA suspension.

The zeta potential-pH curves for HA powder calcined at both 1000 and $1100^{\circ} \mathrm{C}$ with various concentrations of both PAA and SPA are shown in figures 13 and 14, respectively.

Both figures revealed that increasing both $\mathrm{pH}$ and concentration of dispersing agent are responsible for increasing the particle surface charge. However, it was found that SPA develop much higher negative charge on the HA particles than done by the using of PAA dispersant. This means that SPA could be much powerful dispersant for stabilizing HA suspension than PAA. In addition the differences in zeta potential values are not so large between the two types of dispersant. In order to decide whether SPA or PAA is much powerful in stabilizing HA suspension a study for the
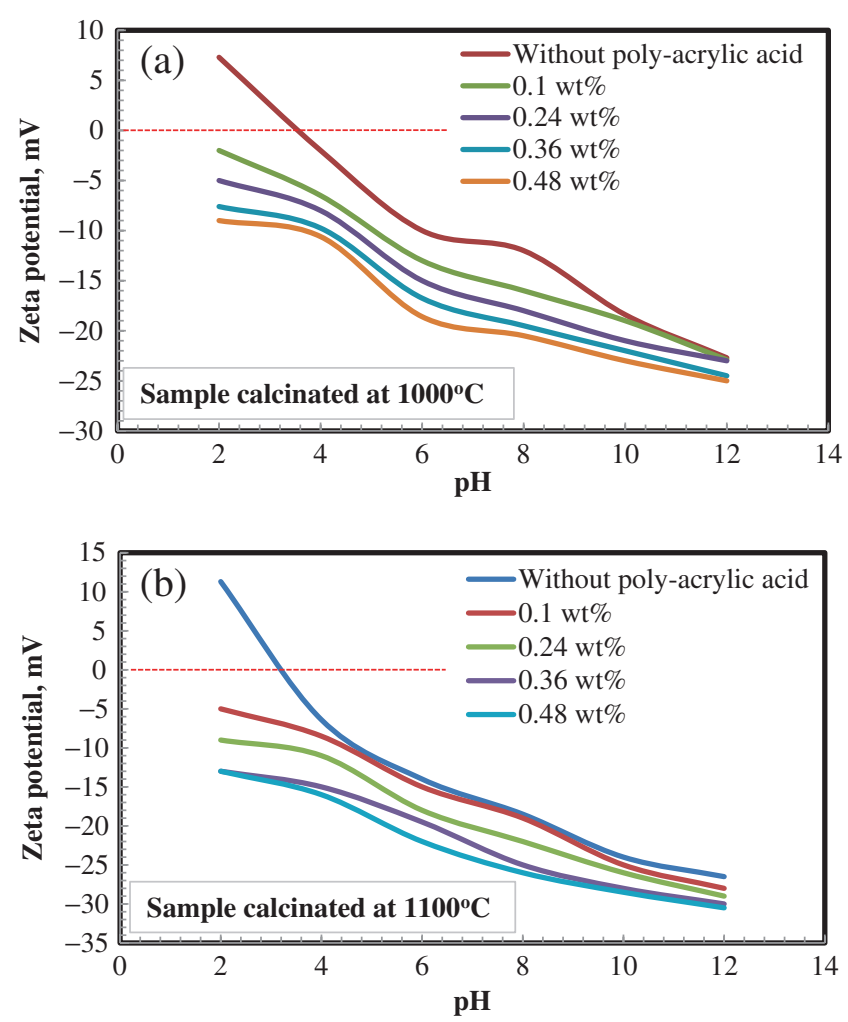

Figure 13. Zeta potential-pH relationship of hydroxyapatite powder with the addition of different weight percentages of polyacrylic acid: $\mathrm{A}=$ sample calcined at $1000^{\circ} \mathrm{C}$ and $\mathrm{B}=$ sample calcined at $1100^{\circ} \mathrm{C}$. 

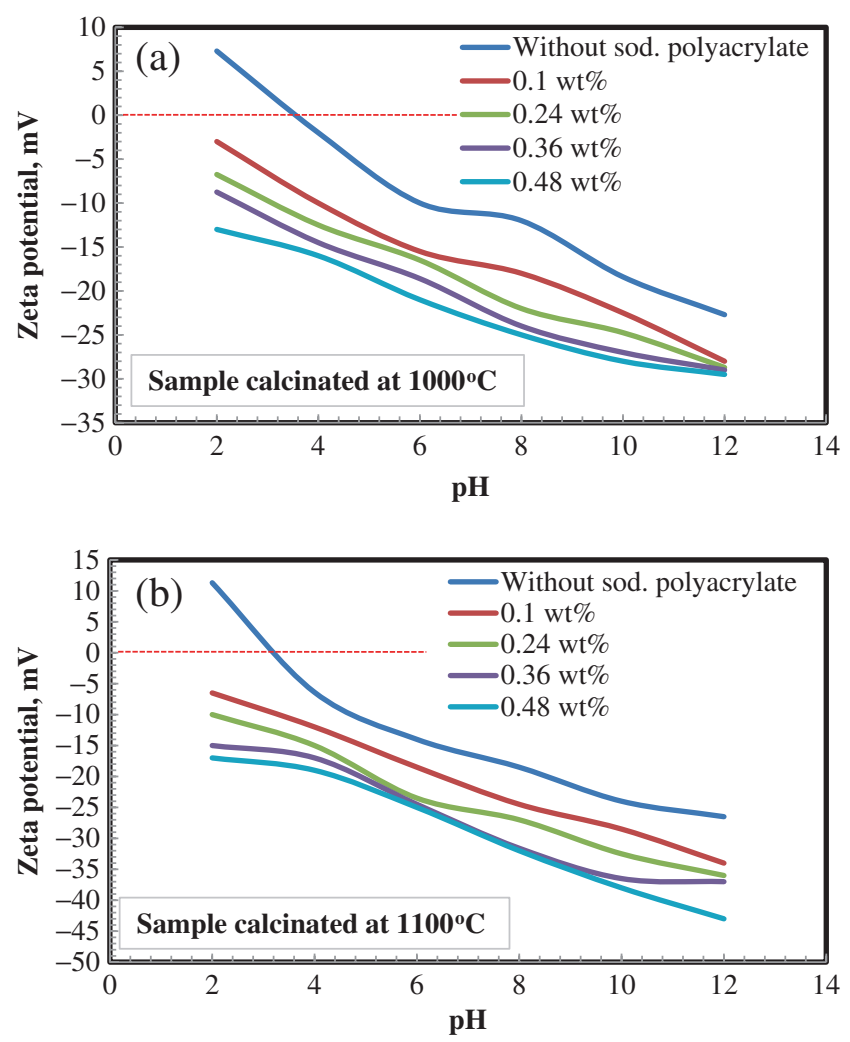

Figure 14. Zeta potential-pH relationship of hydroxyapatite powder with the addition of different weight percentages of sodium polyacrylate: $\mathrm{A}=$ sample calcined at $1000^{\circ} \mathrm{C}$ and $\mathrm{B}=$ sample calcined at $1100^{\circ} \mathrm{C}$.

viscosity and turbidity of these suspensions with the addition of different concentrations of both the dispersants should be investigated. Also, it could be noticed that at $\mathrm{pH} \sim 11$ a higher negative charge for HA particles was obtained whatever the calcination temperature as well as the type and amount of dispersants. The HA sample calcined at $1100^{\circ} \mathrm{C}$ was found to possess higher zeta potential than that of the sample calcined at the $1000^{\circ} \mathrm{C}$ at all conditions of measuring. This could attribute to the fact that traces of carbonate ions could be exists in sample calcined at the $1000^{\circ} \mathrm{C}$ as previously discovered from the FT-IR analysis (figure 6).

\subsection{Effect of type and amount of dispersing agent on viscosity and turbidity of HA suspension}

Suspensions of $20 \mathrm{wt} \%$ solid loading from both powders calcined at 1000 and $1100^{\circ} \mathrm{C}$ were prepared for the measurements of both viscosity and turbidity of the suspensions.

For viscosity measurement a constant shear rate of $250 \mathrm{~s}^{-1}$ was applied. Figures 15 and 16 show the effect of both type and amount of dispersants on the viscosity of suspensions prepared from powder calcined at both 1000 and $1100^{\circ} \mathrm{C}$. These figures revealed that with the increase in time the viscosity of all suspensions is largely decreased. This is an indication of the shear thinning behaviour of such suspensions. On the other hand it was noticed that a minimum viscosity
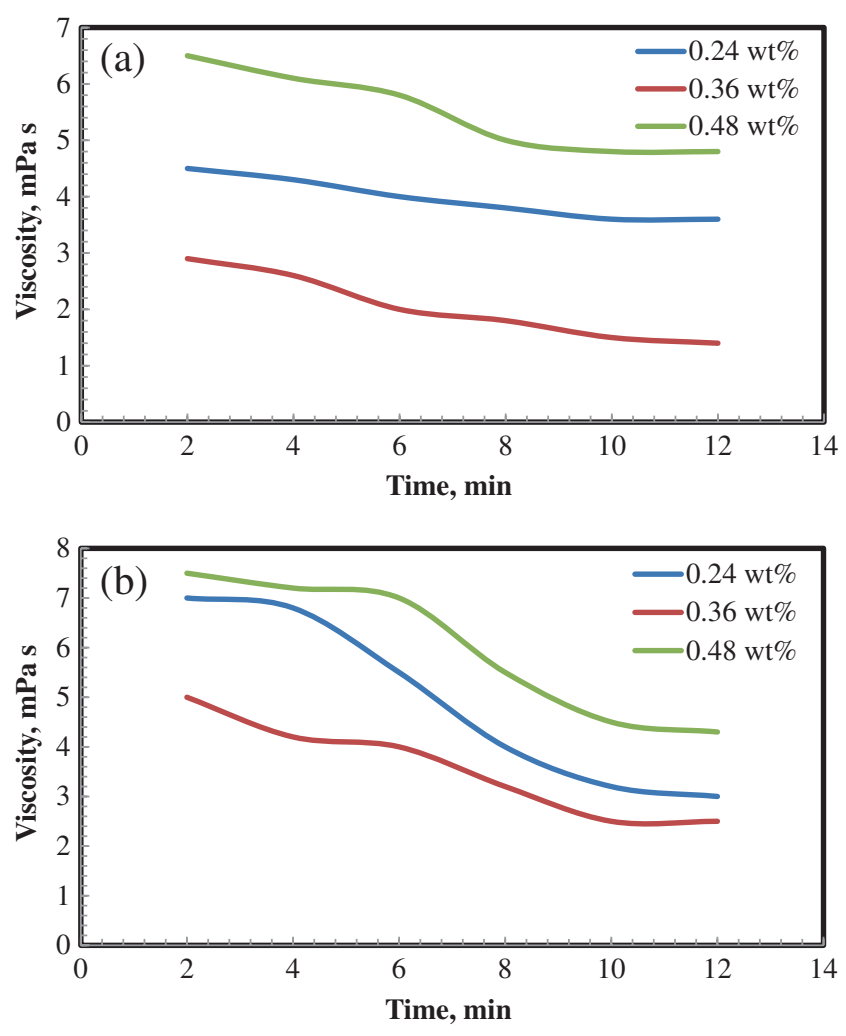

Figure 15. Viscosity of $20 \%$ solid loading hydroxyapatite powder with the addition of different weight percentages of polyacrylic acid: $\mathrm{A}=$ sample calcined at $1000^{\circ} \mathrm{C}$ and $\mathrm{B}=$ sample calcined at $1100^{\circ} \mathrm{C}$.

was observed at $0.36 \mathrm{wt} \%$ for both dispersant additions. This observation revealed that the $0.36 \mathrm{wt} \%$ of dispersant correlate with the optimum concentration for complete coverage of dispersant on ceramic particles creating a maximum repulsive potential, resulting in a low viscosity suspension. ${ }^{50}$ At this amount of dispersant the system is reached what's called saturation absorption point. At this point the dissociated SPA and PAA may cover the surface of all HA particles and these particles would behave a monodispersed particle due to electrosteric stabilization resulting in obtaining a lower viscosity HA suspension. At the lower amount addition of dispersant $(0.24 \mathrm{wt} \%)$ a non-complete coverage of HA particles is obtained, consequently the produced electrical double layer is not enough to achieve an effective inter-particles repulsion and prevails the attraction between them. ${ }^{21}$ When the amount of dispersant is higher than the saturated absorption point, the free polyelectrolyte would exist in the aqueous medium. This causes the electrical double layer to be compressed by too high electrolyte concentration and makes the electrostatic repulsion less effective and consequently the viscosity increased. ${ }^{21}$ Also the increase in the amount of dispersant may cause interlocking of polyelectrolyte chain, which bridged the solid particles and caused increase in the suspension viscosity. ${ }^{25}$

This previous phenomenon of the presence of the optimum amount of dispersant for producing lowest HA suspension viscosity could be rather confirmed from the turbidity 

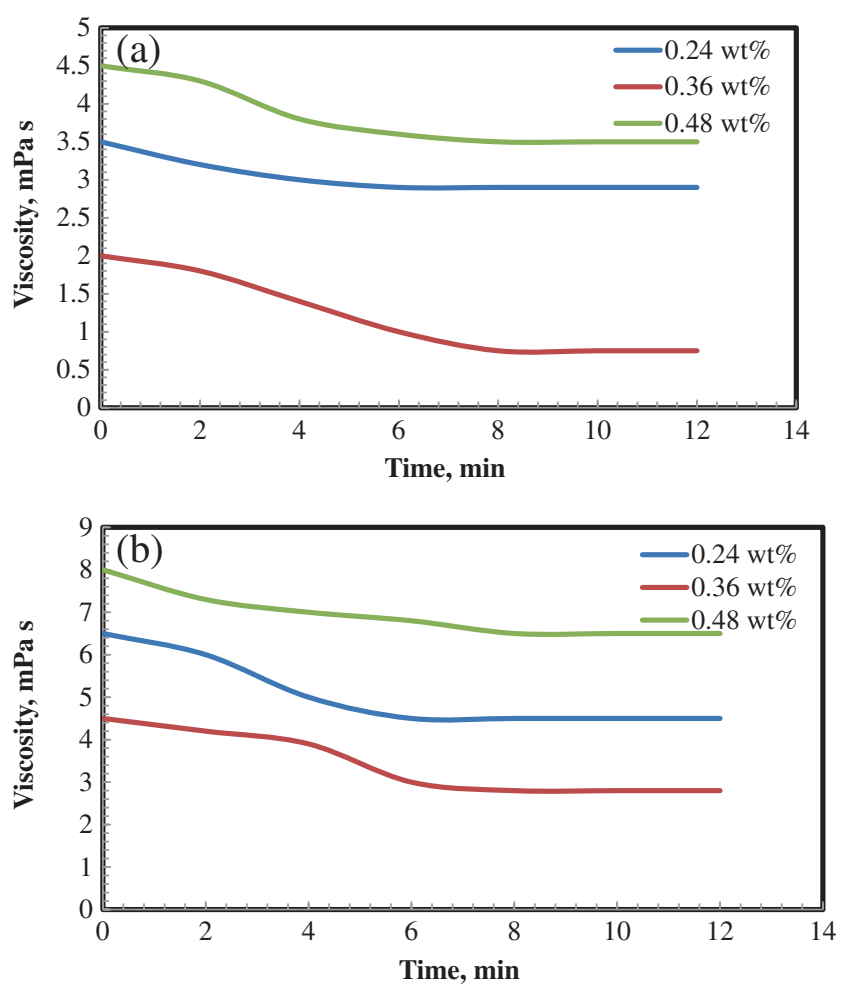

Figure 16. Viscosity of $20 \%$ solid loading hydroxyapatite powder with the addition of different weight percentages of sodium polyacrylate: $\mathrm{A}=$ sample calcined at $1000^{\circ} \mathrm{C}$ and $\mathrm{B}=$ sample calcined at $1100^{\circ} \mathrm{C}$.
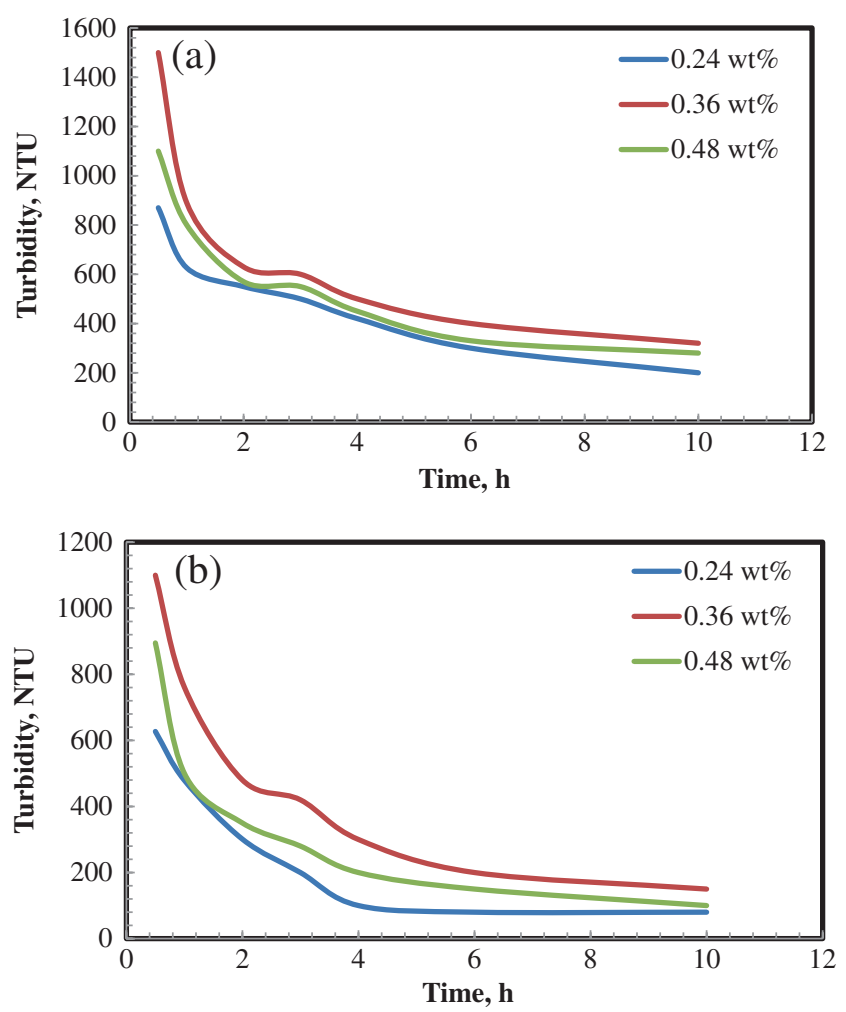

Figure 17. Turbidity measurement of hydroxyapatite powder with the addition of different weight percentages of polyacrylic acid: A $=$ sample calcined at $1000^{\circ} \mathrm{C}$ and $\mathrm{B}=$ sample calcined at $1100^{\circ} \mathrm{C}$.
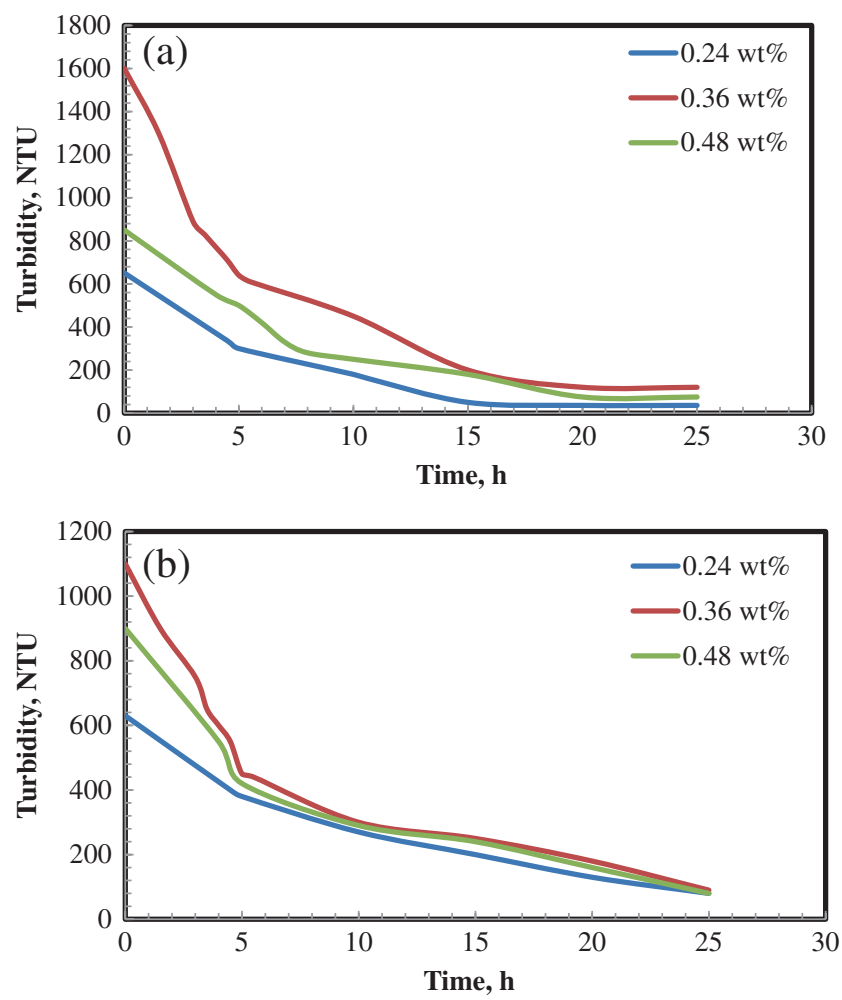

Figure 18. Turbidity measurement of hydroxyapatite powder with the addition of different weight percentages of sodium polyacrylate: $\mathrm{A}=$ sample calcined at $1000^{\circ} \mathrm{C}$ and $\mathrm{B}=$ sample calcined at $1100^{\circ} \mathrm{C}$.

measurements shown in figures 17 and 18. All figures 17A, $\mathrm{B}$ and $18 \mathrm{~A}, \mathrm{~B}$ show that the turbidity degree is higher with the addition of $0.36 \mathrm{wt} \%$ of both dispersant. Increasing the amount of dispersant than this value leads to a high decrease in the degree of turbidity. This observation rather confirmed the interpretation of the presence of the optimum amount of dispersant in order to achieve a lowest HA suspension viscosity.

\section{Conclusions}

In conclusion, the heat treatment step plays a really significant part in moderating the various physical as well as chemical properties of HA powders. A well-crystallized HA powder was achieved with the increase in the calcination temperature while both crystalline size and particle size were largely increased. The carbonate ion content is largely reduced with the increase in the calcination temperature and it is almost eliminated when the calcination temperature reaches $1100^{\circ} \mathrm{C}$. Also, the high decrease in the specific surface area as well as the pore size and its distribution with the increase in calcination temperatures, helps in preparing of a well-stabilized HA suspension of high solid loading. Zeta potential measurements confirmed the development of high negative charge on HA particles calcined at high temperature. Temperatures of 1000 and $1100^{\circ} \mathrm{C}$ were 
proven to be extremely desirable for producing HA powder possesses reasonable physical and chemical properties for developing well-stabilized HA suspension. Moreover, sodium polyacrylate was found to be much more effective dispersing agent in developing high zeta potential value on HA particles than PAA. Viscosity and turbidity measurements define that there is an optimum amount of dispersant agent for producing HA suspension of lower viscosity and high turbidity degree.

\section{References}

1. Cao W and Hench L L 1996 Ceram. Int. 22493

2. Daculsi G 1998 Biomaterials 191473

3. Yamada S, Heymann D, Bouler J M and Daculsi G 1997 J. Biomed. Mater. Res. 37346

4. De Groot 1980 Biomaterials 147

5. Suchanek W and Yoshimura M 1998 J. Mater. Res. 1394

6. With G, Dijk H J A, Hattu N and Prijs K 1981 J. Mater. Sci. 16 1592

7. Yasuda H Y, Mahara S, Umakoshi Y, Imazato S and Ebisu S 2000 Biomaterials 212045

8. Zhang J, Maedab M, Kotobuki N, Hirose M, Ohgushi H, Jiang D and Iwasa M 2006 Mater. Chem. Phys. 99398

9. Padilla S, Carrodeguas R G and Vallet-Reg M 2004 J. Eur. Ceram. Soc. 242223

10. Juang H Y and Hon M H 1997 Ceram. Int. 23383

11. Koh Y H, Kim H W and Kim H E 2002 J. Am. Ceram. Soc. 85 2578

12. Zhang Y, Yokogawa Y, Feng X, Tao Y and Li Y 2010 Ceram. Int. 36107

13. Tan C Y, Tolouei R, Ramesh S, Yap B K and Amiriyan M 2011 BIOMED 2011 Ninth international conference on modelling in medicine and biology (Riga, Latvia)

14. Patel N, Gibson I R, Ke S, Best S M and Bonfield W $2001 \mathrm{~J}$. Mater. Sci.: Mater. Med. 12181

15. Kupiec A S, Wzorek Z, Kijkowska R and Kowalski Y 2013 Bull. Mater. Sci. 36755

16. Juang H Y and Hon M H 1996 Biomaterials 172059

17. Figueiredo M, Fernando A, Martins G, Freitas J, Judas F and Figueiredo H 2010 Ceram. Int. 362383

18. Toque J A, Herliansyah M K, Hamdi M, Ide-Ektessabi A and Wildan M W 2007 Biomed 2006, 3rd Kuala Lumpur international conference on biomedical engineering 2006 (Kuala Lumpur, Malaysia)

19. Ahmed S and Ahsan M 2008 Bangladesh J. Sci. Ind. Res. 43 501

20. Vijayalakshmi U and Rajeswari S 2006 Trends Biomater. Artif. Organs 1957

21. Landi E, Celotti G, Logroscino G and Tampieri A 2003 J. Eur. Ceram. Soc. 232931

22. Landi E, Tampieri A, Celotti G and Sprio S 2000 J. Eur. Ceram. Soc. 202377
23. Sanosh K P, Chu M C, Balakrishan A, Kim T N and Cho S J 2009 Bull. Mater. Sci. 32465

24. Klinkaewnarong J and Maensiri S 2010 Chiang Mai J. Sci. 37 243

25. Tian T, Jiang D, Zhang J and Lin Q 2007 J. Eur. Ceram. Soc. 272671

26. Bouyer E, Gitzhofer F and Boulos M I 2000 J. Mater. Sci. Mater. Med. 11523

27. Pratihar S K, Garg M, Mehra S and Bhattacharyya S $2006 J$. Mater. Sci.: Mater. Med. 17501

28. Alqap A S F and Sopyan I 2009 Indian J. Chem. 48A 1492

29. Mobasherpour I, Heshajin M S, Kazemzadej A and Zakeri M 2007 J. Alloys Compd. 430330

30. Bose S and Saha S K 2003 Chem. Mater. 154464

31. Guo G, Sun Y, Wang Z and Guo H 2005 Ceram. Int. 31869

32. Donadel K, Laranjeira M C M, Goncalves V L, Favere V T, De Lima J C and Prates L H 2004 J. Am. Ceram. Rev. 1043893

33. Xu G, Aksay I A and Groves J T $2001 \mathrm{~J}$. Am. Chem. Soc. 123 2196

34. Lin K, Chang J, Cheng R and Ruan M 2007 Mater. Lett. 61 1683

35. Sun Y, Guo G, Wang $Z$ and Guo H 2006 Ceram. Int. 32951

36. Fernandes G F and Laranjeira M C M 2000 Quim. Nova 23 441

37. Sopyan I, Singh R and Hamdi M 2008 Indian J. Chem. 47A 1626

38. Elliott J C 1994 Structure and chemistry of the apatites and other calcium orthophosphates (Amsterdam: Elsevier) p 387

39. Moens P, Callens F, Matthys P, Maes F, Verbeeck R and Naessens D 1991 J. Chem. Soc. Farad. Trans. 873137

40. Gibson I R, Rahman I, Best S M and Bonfield W 2000 J. Mater. Sci. Mater. Med. 11533

41. Randolph A D and Larson M A 1986 Theory of particulate processes (New York: Academic Press) 2nd ed., p 369

42. Morales J G, Burgues J T and Clemente R R 2001 Cryst. Res. Technol. 361065

43. Saeri M R, Afshar A, Ghorbani M, Ehsani N and Sorrell C C 2003 Mater. Lett. 574064

44. Bhattacharjee S, Swain S K, Sengupta D K and Singh B P 2006 Colloids Surf. A: Physicochem. Eng. Aspects 277164

45. Sadeghian Z, Heinrich J G and Moztarzadeh F 2006 Ceram. Int. 32331

46. Navizi T, Salahi E, Ghafari M and Mobasherpour I 2010 Ceram. Int. 361945

47. Lelievre F, Bernach-assollant D and Chartier T 1996 J. Mater. Sci. Mater. Med. 7489

48. Corradi A B, Manfredini T, Pellacani G C and Pozzi P $1994 J$. Am. Ceram. Soc. 77509

49. Baklouti S, Pagnoux C, Chartier T and Baumard J F 1997 J. Eur. Ceram. Soc. 171387

50. Cyster L A, Grant D M, Howdle S M, Rose F R A J, Irvine D J, Freeman D, Scotchford C A and Shakesheff K M 2005 Biomaterials 26697 